\title{
Remittances as a Shield to Socially-Vulnerable Households in Macedonia: The Case When the Instrument is Not Strictly Exogenous
}

\author{
Dr. Marjan Petreski (University American College, Macedonia) \\ Dr. Blagica Petreski (Association for Economic Research, Advocacy and Policymaking \\ "Finance Think", Macedonia) \\ Despina Petreska ("Finance Think", Macedonia)
}

\begin{abstract}
The objective of the paper is to investigate if remittances sent to Macedonia have a role to play for shielding socially-vulnerable households. To that end, we devise an index of social vulnerability, comprehending income poverty, unemployment of both spouses, single parents, as well conditions of impaired health, undernourishment, material deprivation and insufficient clothing, so as to capture non-income vulnerability conditions. Remittances then are allowed to determine the index of vulnerability. As remittances are likely endogenous to vulnerability, we use the noneconomic motive to migrate as instrument, as it is likely correlated with remittances, since any migrant is likely to send remittances irrespective of his migration motive; while uncorrelated with the shocks onto vulnerability. We use the Remittances Survey 2008 and conditional mixed process (CMP) estimator. Results suggest that remittance-receiving households have, on average $6 \%$ higher probability to report zero-vulnerability, suggesting that they indeed could act as social protection. However, as the assumption of noneconomic motive for migration being a good instrument may be easily dismantled, we further pursue Conley et al.'s (2012) method, allowing for a direct link between noneconomic motive and vulnerability. Results suggest that if we have a reasonable belief that they are determined simultaneously, or directly correlated due to the existence of a third unobservable factor, then it is reasonable to consider that this influence slightly reduces the effect of remittances on vulnerability.
\end{abstract}

\section{Introduction}

Poor households in Macedonia, as elsewhere, face risks from different origin, but the most prominent being the lack of or limited access to formal social insurance and formal credit finance. On the other hand, Macedonia receives about $20 \%$ of its GDP in private transfers per year, out of which it is estimated that at least half are pure cash remittances directly contributing to the livelihoods of (poor) households of Macedonian citizens (Petreski and Jovanovic, eds., 2013). Petreski and Jovanovic (2014) find that remittances sent to Macedonia significantly reduce poverty and increase income equity, while Petreski and Mojsoska (2014) find that while they could overall deter people from investing, the opposite holds for youth in households receiving remittances. Hence, the available studies for Macedonia document large developmental potential of remittances.

On the other hand, the economy is still diving into flagrant unemployment of $29 \%$ and a poverty of $27 \%$ in 2014. Only $9 \%$ of households receive formal social assistance from the government, and it reduces the incidence of poverty by only 3 percentage points. In addition, Mojsoska et al. (2013) argue that the assistance triggers inactivity and laziness. So, it is likely that the formal social assistance does not exert (large) positive role in Macedonia. However, these figures reflecting facets of economic development do not take into account the effect of remittances. Remittances are not a part of the official regular surveys and policies. They are frequently channelled through unofficial-unregistered channels (at least half of them; Petreski and Jovnanovic, 2013). Hence, the bold question emerging is the extent to which remittances serve informal social-protection agreements in handling social risks (Dercon, 2002) and potentially prevent social unrest.

The theory behind the role of remittances and migration as informal social protection for receivers dates back to the new economics of labour migration (Stark, 1978, 1991). This strand of theoretical underpinnings link the causes and consequences of migration explicitly, so that both positive and negative development effects are possible. Particularly, this strand of literature puts the household, not the individual as the decision-making unit with regard to the migration decisions (Taylor, 1999). Hence, if the households is exposed to social risks and income shocks, it will opt for diversification of its labour resources so as to minimize these risks (Stark and Levhari, 1982). This is done by sending a migrant abroad, so that the incidence of income shocks and hence falling into poverty is minimized by diversification of income sources and remittances serve as (informal) social insurance at origin (Lucas and Stark, 1985). Therefore, this approach adds the household-level decisions to the individual-level decisions, as the latter are mainly driven by the self-interest, i.e. the objective to maximize personal income. At the empirical front, the consumption and investment effects of remittances have been widely investigated: some papers date back to 1987, like Lucas, while others are quite recent, e.g. Javid et al. (2012), suggesting that the topic of remittances has not lost of its warmth over the decades. However, the potential of remittances to act as informal social protection and insurance mechanisms in a broader sense has been rarely 
investigated (Sabates-Wheeler and Waite, 2003). Essentially, bulk of the literature relates migration and formal social protection only from the migrants' perspective and the protection options they have in different stages of the migration process. On the other hand, as Sabates-Wheeler and Waite (2003) clearly point out (p.17), migration and hence, remittances have only informal protective role for migrant's family at origin, if not framed by the government in a specific policy. This is also the highlight of De la Briere et al.'s (1997) models of remittances' role: “...migration may be conceptualized as an informal preventive social protection strategy used by migrant households for insurance and risk diversification” (Sabates-Wheeler and Waite, 2003, p.19). However, to the best of our knowledge, remittances have not been framed by governments in specific formal social-protection mechanisms.

The objective of the paper is to investigate if remittances sent to Macedonia have a role to play for shielding socially-vulnerable households. To that end, we devise an index of social vulnerability, comprehending income poverty, unemployment of both spouses, single parents, as well conditions of impaired health, undernourishment, material deprivation and insufficient clothing, so as to capture non-income vulnerability conditions. We regress the index on a standard set of household and community characteristics, adding an indicator of if the households is a recipient of remittances. As remittances are likely endogenous to vulnerability, we use an instrumental variable approach and the conditional mixed process estimator. An indicator of a noneconomic motive to migrate is proposed as instrument, as it is likely correlated with remittances, since any migrant is likely to send remittances irrespective of his migration motive; while uncorrelated with the shocks onto vulnerability. We use the Remittances Survey 2008.

Results suggest that remittance-receiving households have, on average $6 \%$ higher probability to report zerovulnerability, suggesting that they indeed could act as social protection. However, as the assumption of noneconomic motive for migration being a good instrument may be easily dismantled, we further pursue Conley et al.'s (2012) method, allowing for a direct link between noneconomic motive and vulnerability. Results suggest that if we have a reasonable belief that they are determined simultaneously, or correlated due to the existence of a third unobservable factor, then it is reasonable to consider that this influence slightly reduces the effect of remittances on vulnerability.

The next section discusses the index of vulnerability and the economic model used. Section 3 reviews the data and methodology. Section 4 presents the data and offers a discussion. The last section concludes.

\section{Index of Vulnerability and Economic Model}

The most important task in vulnerability assessment is the identification of suitable vulnerability indicators and the construction of an overall vulnerability index. There is no consensus in the literature on the indicators defining vulnerability at the individual or household level. The micro-triggers of vulnerability (i.e. those affecting wellbeing negatively) could be loss of job (and hence income), illness, death and the like. In their effort to construct a vulnerability index, Rygel et al. (2005) used the following vulnerability indicators: poverty, gender, race and ethnicity, age, and disabilities. They argued that the most important manifestation of vulnerability is the income shortfall and hence took poverty as indicator of vulnerability. They argued that poor people have less money to spend on preventative measures, emergency supplies, and recovery efforts (Clark et al. 1998). However, a large strand of the literature goes beyond poverty in measuring vulnerability, although many of them refer to country and not the household level. For example, Adger et al. (2004) defined a couple of categories of vulnerability indicators, out of which the following refer to the household vulnerability: economic wellbeing - income and employment; health and nutrition. Given these notions, this paper is based on a vulnerability index which is composed of the following facets of vulnerability:

1. Income poverty, as the most direct measure of the well-being and being the only direct income-based vulnerability indicator;

2. Unemployment of two spouses in households with at least one child;

3. Single (lone) parents;

4. Households with bad health conditions;

5. Households with bad housing conditions;

6. Households who are undernourished;

7. Households with endangered health condition of members;

8. Households without availability of different forms of leisure.

Devised through these components, Table 1 presents the distribution of the Vulnerability index for Macedonia. It suggests that more than one third of the households in Macedonia, 37.6\% do not reveal any of the vulnerability condition. Nearly one third, $30.9 \%$, revealed only one condition of vulnerability. The shares significantly decline as we progress up the vulnerability scale: very vulnerable households, which could be arbitrarily taken those with an index of above 5 are only few: $2.3 \%$ of all households. 


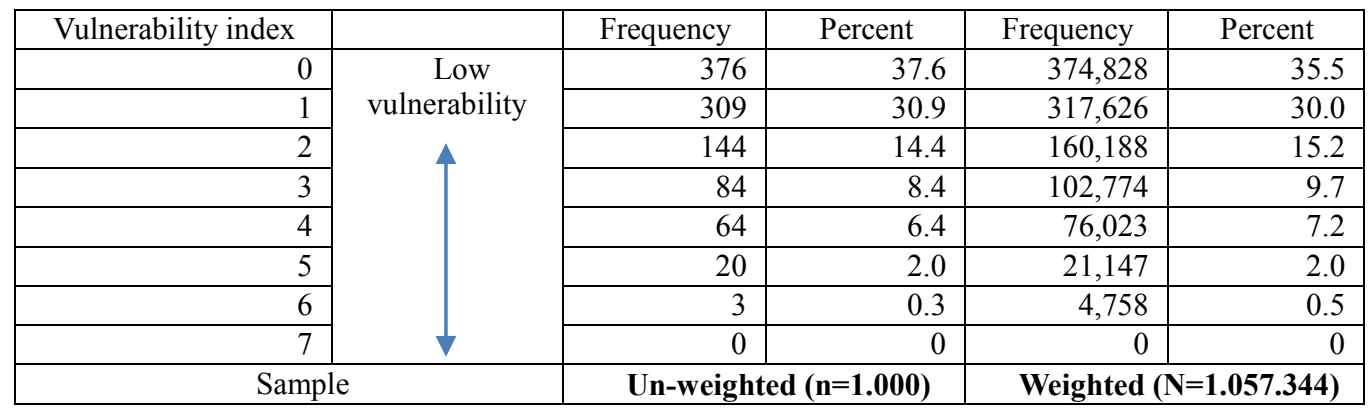

Table 1 - Distribution of the overall Vulnerability index for Macedonia Source: Authors' calculations.

We use this index obtained as a dependent variable in a fairly standard model in order to identify how different personal and household characteristics affect vulnerability. As our analysis is at the household level, any personal characteristic refers to that of the household head. We will write the model in the following generic form:

$V I_{i}=\alpha+\sum \beta_{1 i}$ Head_ch $_{i}+\sum \beta_{2 i}$ Household $_{i}+\sum \beta_{3 i}$ Community $_{i}+\gamma *$ Remit $_{i}+\varepsilon_{i}$

Whereby $V I_{i}$ stands for the Vulnerability Index of household i, as defined above; Head_ch $i$ captures a bunch of personal characteristics of the household head; Household $i$ captures a set of household-level characteristics, ${\text { while } \text { Community }_{i} \text { some community/regional level characteristics. The central variable of interest, Remit }}_{i}$ measures remittances and is expressed as a dummy variable by separating receiving from non-receiving households, so as any measurement issues (underreporting) of remittances is avoided. $\varepsilon_{i}$ is the error term which is assumed to be well behaved.

The explanatory variables that enter equation 1 are based on the literature. Gender affects vulnerability: women are more vulnerable than men, mainly because women - especially divorced mothers and never-married mothers - are more likely to live in poverty (Bianchi and Spain, 1996). Hence, being married or not may be also affecting vulnerability. Ethnicity may matter also: Fothergill et al. (1999) argued that racial minorities in the US are more vulnerable than whites because minorities are more likely to be poor. Discrimination also plays a major role in increasing the vulnerability of racial and ethnic groups. Further, both young and old people may be unable to respond to shocks on their own. Children who lack adequate family support are at a major disadvantage for disaster response. The elderly are more likely to lack the necessary physical and economic resources to respond effectively to a disaster (Morrow, 1999). Adger et al. (2004) inter alia identified less education and less endowed with social capital households as more prone to shocks and hence more vulnerable. Hence, in (1) we use the following explanatory variables: the age of the head and its square, gender, marriage, ethnicity (where available), education of the head (measured on an ordered scale from 1 - no education to 9 - holding a PhD), number of household members and its square, dependency ratio (measured as the share of children, students and persons older than 64 in the total number of household members) and an indicator of whether the household lives in an urban or rural area.

\section{Data and Methodological Concerns}

We use the Remittances Survey 2012. The Survey has been collected by the University American College Skopje within a previous effort to analyze poverty and inequality nexus with remittances (see, Petreski and Jovanovic, 2014). The survey comprehends about 60 questions specifically focused on remittances and little to migration. It also captures the socio-economic and demographic variables, making it suitable for the analysis we conduct herein.

We have two econometric challenges. The first econometric challenge in estimating (1) is the endogeneity of our variable of interest - remittances. Remittances could suffer endogeneity from two sources: reverse causality; and unobserved factors affecting both remittances and vulnerability. More vulnerable households may be more willing, but less able to send migrants abroad (reversed causality). Or, persons who belong to more vulnerable households may feel larger inclination to emigrate, in which case the unobserved factor - inclination to emigrate, determined both remittances and vulnerability. As remittances are probably measured with error, the OLS estimator will be biased towards zero (the so-called 'attenuation bias'). If we do not observe all facets of household wealth and personal characteristics, there would be omitted variables correlated with both remittances (which are the 'product' of migration) and vulnerability. For instance, households with higher innate 'ability' could be at the same less vulnerable and more likely to attract remittances intended for investment in the local economy, so that vulnerability and remittances would be negatively correlated without a causal relationship. Hence, remittances would tend to be correlated with the unobserved determinants of vulnerability, biasing any OLS estimate (Hanson and Woodruff, 2003). The endogeneity stemming from simultaneity, measurement error, and omitted variables (unobserved variables) is well documented in the literature (see, e.g. Wooldridge, 2002). Hence, the endogeneity between remittances and vulnerability is a major methodological concern. 
Instrumental variable estimators have been widely documented and applied for resolution of this problem (e.g. Amuedo-Dorantes and Pozo, 2006; Hanson and Woodruff, 2003; Cameron and Trivedi, 2005). The instrumental variables used to correct the remittances' endogeneity should not affect vulnerability of the household other than through their effect on the remittance income (see Wooldridge, 2002, pp.621). Perfect instruments are rare, though. However, as Petreski et al. (2014) argue, the noneconomic motive to migrate may well sure our purpose.

The variable is a dummy created from the question where the respondent was able to choose (multiple) options from the following: economic reasons, political reasons (including war and conflict), education, marriage/family reunion, and other. The dummy takes a value of one for those households who have not selected economic reasons as any of the possible choices. Thus, this variable should not be correlated with the vulnerability of the household, following an assumption that the economic reasons for migrating are uncorrelated with the other reasons.

The second econometric challenge in estimating (1) is that our dependent variable is an ordered variable (as we discussed in Section 2), while our suspected endogenous variable (remittances) is binary variable. From that viewpoint, using any form of IV is problematic: to our knowledge, there is no straightforward application of IV ordered probit; in addition, any genuine IV estimation treats endogenous variables as continuous, which is not the case here. This renders estimates biased and inefficient (Wooldridge, 2007). Roodman (2011) proposed the so called Conditional Mixed Process (CMP) estimator which allows mixing the standard limited dependent variable models in multi-equation systems. The CMP method is a parametric one, meaning that distributional assumptions are imposed on the model which leads to higher efficiency. The standard IV approach, however, does not; there is an implied trade-off between both estimators. The CMP method is appropriate for two broad types of estimation situations: 1) those in which a truly recursive data-generating process is posited and fully modeled; and 2) those in which there is simultaneity but instruments allow the construction of a recursive set of equations, as in two-stage least squares (2SLS) (Roodman, 2011). In the first case, CMP is a full-information maximum likelihood (FIML) estimator, all estimated parameters being structural. In the latter, it is a limitedinformation (LIML) estimator, and only the final stage's (or stages') parameters are structural, the rest being reduced-form.

So, given we have grounds for concern that both simultaneity (i.e. reverse causation), measurement error, and the omitted variables (due to unobserved variability) probably make remittances endogenous in our framework; and, in addition, due to the IV's disadvantages in dealing with ordered dependent variable and continuous endogenous regressors, we will proceed with the CMP approach. Hence, we will estimate the following system of equations:

$\operatorname{Pr}\left(\right.$ Remit $\left._{i}\right)=\alpha_{1}+\sum \beta_{11 i}$ Head_ch $_{i}+\sum \beta_{12 i}$ Household $_{i}+\sum \beta_{13 i}$ Community $_{i}+\sum \delta_{i}$ Inst $_{i}+\varepsilon_{1 i}$ $\operatorname{Pr}\left(V_{i}\right)=\alpha_{2}+\sum \beta_{21 i}$ Head_ch $_{i}+\sum \beta_{22 i}$ Household $_{i}+\sum \beta_{23 i}$ Community $_{i}+\gamma *$ Remit $_{i}+\varepsilon_{2 i}$

Whereby Inst $_{i}$ is the instrumental variable used in the first-stage regression (2) in which the probability that the household gets remittances is regressed on the same bunch of variables explained above and the instruments; while the second-stage regression (3) is the same (1) except that remittances enter after 'purging' from their potential endogeneity in (2).

\section{Results and Discussion}

\subsection{Baseline Results}

Table 2 presents the baseline results. The table is organized so that we first present the estimates for the overall vulnerability index and then we split the index on its income component, which reduces to relative poverty, and on its non-income components, which is all the remaining components. Each time, we first present the first-stage regression (equation 2), and then the second-stage regression (equation 3 ).

The first result to be noted is that only ethnicity and household size significant in the first-stage regression. This suggests that there are systematic differences in who receives remittances only in terms of these two observed characteristics. Macedonians have lower probability than Albanians, while smaller households higher probability to get remittances. Our instrument used - the non-economic motive to migrate is significant. The coefficient suggests that those who migrated for a non-economic reason have, on average, lower probability to send remittances by a large $86 \%$. We turn our attention to the second-stage regression. We start with column (2), whereby the total vulnerability index is used as a dependent variable. Ethnicity, education, the number of household members, dependency ratio and remittances are found significant in determining vulnerability. Ethnic Macedonians are less vulnerable, on average, than compared to ethnic Albanians. Higher education of the household head leads to lower vulnerability. Households which are larger in size are more vulnerable than those which are smaller, while the larger the share of dependent members, the higher the household vulnerability. These results are almost entirely replicated when vulnerability is split on income (column 4) and non-income vulnerability (column 6).

The central variable of interest - remittances - is found significant when considering the overall index and its income component. Households who receive remittances have on average lower vulnerability than those who do 
not. To quantify the effect of remittances on vulnerability, Table 3 gives the marginal effects for the seven outcomes of the vulnerability index. Remittance-receiving households have, on average $6 \%$ higher probability to report zero-vulnerability, i.e. that none of the vulnerability conditions we identified in Section 2 prevailed. This is very strong and, probably, the most important result of this study, suggesting that remittances indeed could act as social protection for remittance-receiving households. Remittance-receiving households have lower probability by, on average, $1.8 \%$ to report two vulnerability conditions than compared to non-receiving households. Afterwards, the effect diminishes to $1.7 \%$ and $1.5 \%$ for prevalence of three and four vulnerability conditions, respectively, and fully vanishes for the largest vulnerability conditions. The main driver of the finding is poverty / income vulnerability, and not non-income vulnerability. Results suggest that households who get remittances have lower probability of falling into poverty by, on average, $27 \%$ than compared to nonreceiving households. The result is similar, but still slightly lower than the one found in Petreski and Jovanovic, eds. (2013). Remittances are found insignificant for each outcome of the non-income vulnerability index (not shown, but available on request).

\begin{tabular}{|c|c|c|c|c|c|c|}
\hline & \multicolumn{2}{|c|}{ Vulnerability index } & \multicolumn{2}{|c|}{ Income vulnerability } & \multicolumn{2}{|c|}{ Non-income vulnerability } \\
\hline & $\begin{array}{c}\text { First stage: } \\
\text { Remittances }\end{array}$ & $\begin{array}{l}\text { Second stage: } \\
\text { Vulnerability }\end{array}$ & $\begin{array}{c}\text { First stage: } \\
\text { Remittances } \\
\end{array}$ & $\begin{array}{l}\text { Second stage: } \\
\text { Vulnerability }\end{array}$ & $\begin{array}{l}\text { First stage: } \\
\text { Remittances }\end{array}$ & $\begin{array}{l}\text { Second stage: } \\
\text { Vulnerability }\end{array}$ \\
\hline & (1) & (2) & (3) & (4) & (5) & (6) \\
\hline \multirow[t]{2}{*}{ Age of the head } & -0.0261 & 0.0366 & -0.0349 & 0.0088 & -0.0255 & 0.0357 \\
\hline & $(0.041)$ & $(0.023)$ & $(0.041)$ & $(0.033)$ & $(0.042)$ & $(0.023)$ \\
\hline \multirow[t]{2}{*}{ Age squared } & 0.0002 & $-0.0005 * *$ & 0.0003 & -0.0001 & 0.0002 & $-0.0005 * *$ \\
\hline & $(0.0000)$ & $(0.0000)$ & $(0.0000)$ & $(0.0000)$ & $(0.0000)$ & $(0.0000)$ \\
\hline \multirow[t]{2}{*}{ Gender $(1=$ male $)$} & -0.1518 & -0.1351 & -0.1497 & 0.0571 & -0.152 & -0.1426 \\
\hline & $(0.202)$ & $(0.102)$ & $(0.202)$ & $(0.155)$ & $(0.203)$ & $(0.104)$ \\
\hline \multirow[t]{2}{*}{$\begin{array}{l}\text { Marital status } \\
(1=\text { married })\end{array}$} & -0.3165 & -0.1616 & -0.3387 & 0.3418 & -0.3255 & -0.2563 \\
\hline & $(0.341)$ & $(0.200)$ & $(0.341)$ & $(0.276)$ & $(0.342)$ & $(0.215)$ \\
\hline \multirow[t]{2}{*}{$\begin{array}{l}\text { Ethnicity } \\
\text { (1=Macedonian) }\end{array}$} & $-0.8548 * * *$ & $-0.1866^{*}$ & $-0.8396 * * *$ & $-0.5587 * * *$ & $-0.8583 * * *$ & -0.0742 \\
\hline & $(0.168)$ & $(0.097)$ & $(0.166)$ & $(0.130)$ & $(0.166)$ & $(0.097)$ \\
\hline \multirow[t]{2}{*}{$\begin{array}{l}\text { Education of the } \\
\text { head (ordered scale) }\end{array}$} & -0.0091 & $-0.1999 * * *$ & -0.0043 & $-0.2321 * * *$ & -0.0101 & $-0.1686^{* * *}$ \\
\hline & $(0.055)$ & $(0.031)$ & $(0.054)$ & $(0.044)$ & $(0.055)$ & $(0.032)$ \\
\hline \multirow[t]{2}{*}{$\begin{array}{l}\text { Number of hh } \\
\text { members }\end{array}$} & $-0.5153 * * *$ & $0.2795 * * *$ & $-0.5190 * * *$ & $0.4580 * * *$ & $-0.5182 * * *$ & $0.2070^{* *}$ \\
\hline & $(0.153)$ & $(0.092)$ & $(0.150)$ & $(0.133)$ & $(0.155)$ & $(0.095)$ \\
\hline \multirow[t]{2}{*}{$\begin{array}{l}\text { Number of hh } \\
\text { members squared }\end{array}$} & $0.0435 * * *$ & -0.0128 & $0.0445 * * *$ & $-0.0207 *$ & $0.0436 * * *$ & -0.0095 \\
\hline & $(0.015)$ & $(0.008)$ & $(0.015)$ & $(0.012)$ & $(0.015)$ & $(0.009)$ \\
\hline \multirow[t]{2}{*}{ Dependency ratio } & -0.3302 & $1.2053 * * *$ & -0.3362 & 0.3054 & -0.324 & $1.2812 * * *$ \\
\hline & $(0.328)$ & $(0.167)$ & $(0.326)$ & $(0.252)$ & $(0.330)$ & $(0.171)$ \\
\hline \multirow[t]{2}{*}{$\begin{array}{l}\text { Geography } \\
\text { (1=urban) }\end{array}$} & 0.2277 & 0.0052 & 0.2247 & -0.125 & 0.2217 & 0.0434 \\
\hline & $(0.174)$ & $(0.082)$ & $(0.176)$ & $(0.114)$ & $(0.174)$ & $(0.084)$ \\
\hline \multirow[t]{2}{*}{$\begin{array}{l}\text { Non-economic } \\
\text { motive to migrate }\end{array}$} & $-0.8611 * * *$ & & $-0.8611 * * *$ & & $-0.8611 * * *$ & \\
\hline & $(0.018)$ & & $(0.018)$ & & $(0.018)$ & \\
\hline \multirow[t]{2}{*}{$\begin{array}{l}\text { Remittances }(1=\text { the } \\
\text { household receives } \\
\text { remittances) }\end{array}$} & & $-0.1629 *$ & & $-0.2658^{*}$ & & -0.1189 \\
\hline & & $(0.095)$ & & $(0.144)$ & & $(0.097)$ \\
\hline \multirow[t]{2}{*}{ Constant } & 0.9647 & & 1.1258 & -0.8993 & 0.9837 & \\
\hline & $(1.051)$ & & $(1.047)$ & $(0.878)$ & $(1.057)$ & \\
\hline Observations & 991 & 991 & 991 & 991 & 991 & 991 \\
\hline
\end{tabular}

Table 2 - Baseline results for Macedonia Source: Authors' calculations. *** and *** denote statistical significance at the 10, 5 and 1\% level, respectively. Standard errors given below each coefficient. 


\subsection{Second Relaxing the Assumption of Strictly Exogenous Instruments}

Despite our argumentation in Section 3, still the main criticism one could throw on our results is, actually, the validity of the instrument used, i.e. its strict exogeneity. In other words, our inference in Section 4.1 assumes that the IV exclusion restriction holds exactly. But, this may not be true. The first step is to think of the potential existence of direct links between the noneconomic motive to migrate and the vulnerability of the sending household. One example is persons leaving in deprivation who may be more inclined to conclude marriage with non-residents. This is not so uncommon for Macedonians, especially given the inclination of children from the diaspora (Macedonians born abroad) to marry Macedonians. Another example is the case of wars and conflicts: they financially and materially deprive households, increasing their inclination to emigrate in order to escape the perils of the war. While this has not been that usual for Macedonia, the war in Bosnia in the 1990s may serve as a good example. Both cases suggest that the direct link between the non-economic motive to migrate and vulnerability may not be so uncommon, though.

Recently, Conley et al. (2012) presented practical methods for performing inference while relaxing the exclusion restriction assumption. They presented "alternative approaches to inference that do not impose the assumption that instruments exactly satisfy an exclusion restriction; they need only be plausibly exogenous" (p.270). The approaches involve using prior information regarding the extent of deviations from the exact exclusion restriction. The argument we use here to justify exclusion restriction - migrants from more vulnerable households may have a tendency to emigrate for a non-economic reason - is providing information about prior beliefs about the violation of this restriction. The contribution of Conley et al. (2012) provides a tool for drawing inference about remittances when noneconomic motive to migrate is an imperfect instrument.

In what follows, hence, we relax the strong exogeneity assumption for our instrument and estimate the remittances impact onto vulnerability with only a plausibly exogenous instrument. The method consists of estimating a modified version of the model given in (2) and (3), and consists of estimating $\gamma$ in the following equation:

$$
\operatorname{Pr}\left(V_{i}\right)=\alpha_{3}+\sum \beta_{31 i} \text { Head_ch }_{i}+\sum \beta_{32 i} H_{H}+\sum \beta_{33 i} \text { Community }_{i}+\gamma * \text { Remit }_{i}+\delta * \text { Inst }_{i}+\varepsilon_{3 i}
$$

where $\delta$ is a measure of the direct relationship of the instrument with the household vulnerability. In the previous estimations, $\delta$ was assumed to equal zero, which could result in a biased estimate of $\gamma$ in case of a direct relationship between the instrument and the dependent variable.

We use an arbitrary span/magnitude of this direct influence of between $0 \%$ and $35 \%$, since we have no other prior information, except that it may be positive (i.e. more vulnerable households may be correlated with higher inclination to emigrate for noneconomic reason). Results are presented in Table 4 and suggest when no direct influence between noneconomic motive and vulnerability is allowed, households receiving remittances have lower chances to be vulnerable. Then, for increasing direct influence between the plausibly exogenous instrument and the dependent variable, the remittances' effect on vulnerability is retained significant up to the $6^{\text {th }}$ percentile, with decreasing magnitude. In other words, results suggest that there is still a significant effect of remittances on vulnerability, even with substantial departures from perfect instruments.

\begin{tabular}{|c|c|c|c|c|c|c|c|c|}
\hline 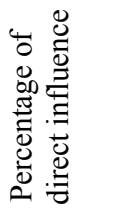 & 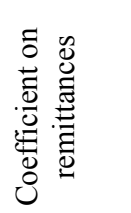 & 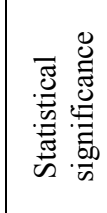 & 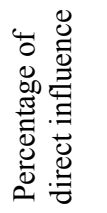 & 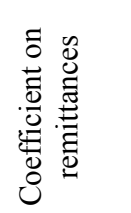 & 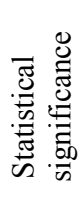 & 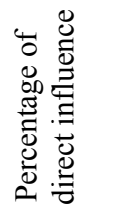 & 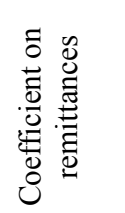 & 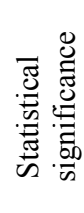 \\
\hline 0 & -0.21488 & $* * *$ & 12 & -0.14521 & & 24 & -0.07554 & \\
\hline 1 & -0.20907 & $* * *$ & 13 & -0.1394 & & 25 & -0.06973 & \\
\hline 2 & -0.20327 & $* * *$ & 14 & -0.1336 & & 26 & -0.06392 & \\
\hline 3 & -0.19746 & $* * *$ & 15 & -0.12779 & & 27 & -0.05812 & \\
\hline 4 & -0.19165 & $* * *$ & 16 & -0.12198 & & 28 & -0.05231 & \\
\hline 5 & -0.18585 & $* * *$ & 17 & -0.11618 & & 29 & -0.04651 & \\
\hline 6 & -0.18004 & & 18 & -0.11037 & & 30 & -0.0407 & \\
\hline 7 & -0.17424 & & 19 & -0.10457 & & 31 & -0.0349 & \\
\hline 8 & -0.16843 & & 20 & -0.09876 & & 32 & -0.02909 & \\
\hline 9 & -0.16262 & & 21 & -0.09295 & & 33 & -0.02328 & \\
\hline 10 & -0.15682 & & 22 & -0.08715 & & 34 & -0.01748 & \\
\hline 11 & -0.15101 & & 23 & -0.08134 & & 35 & -0.01167 & \\
\hline
\end{tabular}

Table 4 - Significance of remittances under the assumption of plausibly exogenous instrument Source: Authors' calculations. * denotes statistical significance at the 5\% level. Confidence intervals not reported to preserve space, but available on request. 
The idea is that if we have a reasonable belief that vulnerability and noneconomic motive are determined simultaneously, or correlated due to the existence of a third unobservable factor, then it is reasonable to consider that this influence slightly reduces the effect of remittances on vulnerability. This makes sense: if migrants originating from more vulnerable households have a tendency to leave for noneconomic reason and send remittances, then remittances may have weaker effect on vulnerability reduction, since those who depart for noneconomic reason likely generate income at destination with a slower pace than those who head for job. However, for medium to large direct influence, remittances are found not to affect vulnerability.

\section{Conclusions}

The objective of the paper is to investigate if remittances sent to Macedonia have a role to play for shielding socially-vulnerable households. To that end, we devise an index of social vulnerability, comprehending income poverty, unemployment of both spouses, single parents, as well conditions of impaired health, undernourishment, material deprivation and insufficient clothing, so as to capture non-income vulnerability conditions.

We regress the index on a standard set of household and community characteristics, adding an indicator of if the households is a recipient of remittances. As remittances are likely endogenous to vulnerability, we use an instrumental variable approach and the conditional mixed process estimator. An indicator of a noneconomic motive to migrate is proposed as instrument, as it is likely correlated with remittances, since any migrant is likely to send remittances irrespective of his migration motive; while uncorrelated with the shocks onto vulnerability. We use the Remittances Survey 2008.

Results suggest that remittance-receiving households have, on average $6 \%$ higher probability to report zerovulnerability, suggesting that they indeed could act as social protection. However, as the assumption of noneconomic motive for migration being a good instrument may be easily dismantled, we further pursue Conley et al.'s (2012) method, allowing for a direct link between noneconomic motive and vulnerability. Results suggest that if we have a reasonable belief that they are determined simultaneously, or correlated due to the existence of a third unobservable factor, then it is reasonable to consider that this influence slightly reduces the effect of remittances on vulnerability.

\section{References}

- $\quad$ Adger, W.N., Brooks, N., Bentham, G., Agnew, M. and Eriksen, S. (2004). New indicators of vulnerability and adaptive capacity. Tyndall Centre Technical Report 7, Tyndall Centre for Climate Change Research Norwich, UK

- Amuedo-Dorantes, C. and Pozo, S. (2006) Migration, Remittances, and Male and Female Employment Patterns. The American Economic Review, 96(2), p.222-226.

- Bianchi, S.M. and Spain, D. (1996). Women, work, and family in America. Population Bulletin 51(3), Population Reference Bureau.

- $\quad$ Clark, G., Moser, S., Ratick, S., Dow, K., Meyer, W., Emani, S., Jin, W., Kasperson, J., Kasperson, R. and Schwarz, H.E. (1998). Assessing the vulnerability of coastal communities to extreme storms: The case of Revere, MA., USA. Mitigation and Adaptation Strategies for Global Change 3, 59-82

- Conley, T.G., Hansen, C.B. and Rossi, P.E. (2012) Plausibly exogenous. The Review of Economics and Statistics, 94(1): 260-272.

- De la Briere, B., De Janvry, A., Lambert, S. and Sadoulet, E. (1997) Why Do Migrants Remit? An Analysis for the Dominican Sierra, International Food Policy Research Institute, Food Consumption and Nutrition Division, Discussion Paper No. 37.

- Dercon, S. (2002) Income Risk, Coping Strategies, and Safety Nets. World Bank Research Observer, Oxford University Press, vol. 17(2), pages 141-166, September.

- $\quad$ Fothergill, A., Maestas, E.G.M. and Darlington, J.D. (1999). Race, ethnicity and disasters in the United States: A review of the literature. Disasters 23(2), 156-173

- Hanson, G.H. and Woodruff, C. (2003) Emigration and Educational Attainment in Mexico. UCSD working paper, 2003.

- Javid, M., Arif, U. and Qayyum, A. (2012) Impact of remittances on economic growth and poverty. Academic Research International, Vol. 2, No. 1.

- $\quad$ Lucas, R. and Stark, O. (1985). Motivations to remit: Evidence from Botswana. Journal of Political Economy 93, 901-918.

- Mojsoska-Blazevski, N., Petreski, M. and Petreska, D. (2013) Increasing labour market activity of poor and female: Let's make work pay in Macedonia. EUROMOD Working Paper Series, EM16/13.

- $\quad$ Morrow, B.H. (1999). Identifying and mapping community vulnerability. Disasters 23, 1-18 
- $\quad$ Petreski, M. and Jovanovic, B. (2014) Do Remittances Reduce Poverty and Inequality in the Western Balkans? Evidence from Macedonia. MPRA Paper 51413.

- $\quad$ Petreski, M. and Jovanovic, B. eds. (2013). Remittances and Development in the Western Balkans: The cases of Macedonia, Kosovo and Bosnia-Herzegovina. Scholars' Press.

- Petreski, M. and Mojsoska, N. (2014) Youth self-employment in households receiving remittances in Macedonia. PEP report.

- Roodman, D. (2011) Fitting fully observed recursive mixed-process models with cmp. The Stata Journal, 11(2), p.159-206.

- Rygel, L., Sullivan, D. and Yarnal, B. (2006). A method for constructing a social vulnerability index: an application to hurricane storm surges in developed countries. Mitigation and adaptation strategies for global change 11, 741-764

- Sabates-Wheeler, R. and Waite, M. (2003) Migration and Social Protection: A Concept Paper. Working Paper of the Institute of Development Studies, Sussex.

- Stark, O. (1978) Economic-Demographic Interactions in Agricultural Development: The Case of Rural-to Urban Migration. Food and Agriculture Organization of the United Nations, Rome.

- Stark, O. (1991) The Migration of Labor. Blackwell, Cambridge and Oxford.

- $\quad$ Stark, O. and Levhari, d. (1982) On Migration and Risk n LDCs. Economic Development and Cultural Change, 31(1), p.191-196.

- Taylor, J.E. (1999) The New Economics of Labor Migration and the Role of Remittances in the Migration Process. International Migration, 37(1), p.63-88.

- Wooldridge, J.M. (2002) Econometric Analysis of Cross Section and Panel Data. London: The MIT Press.

- Wooldridge, J.M. (2007) Introductory Econometrics: A Modern Approach. London: The MIT Press. 